\title{
Building a Floating Hydroponic Garden ${ }^{1}$
}

\section{Sweat, R. Tyson, R. Hochmuth ${ }^{2}$}

The Aztecs and Incas amazed the Spanish conquistadors with their floating gardens, and now 500 years later you can impress your friends and neighbors with yours. A floating hydroponic garden is easy to build and can provide a tremendous amount of nutritious vegetables for home use, and best of all, hydroponic systems avoid pest problems commonly associated with the soil. This simple guide will show you how to build your own floating hydroponic garden using material locally available at a cost of about $\$ 40.00$ (Figure 1).

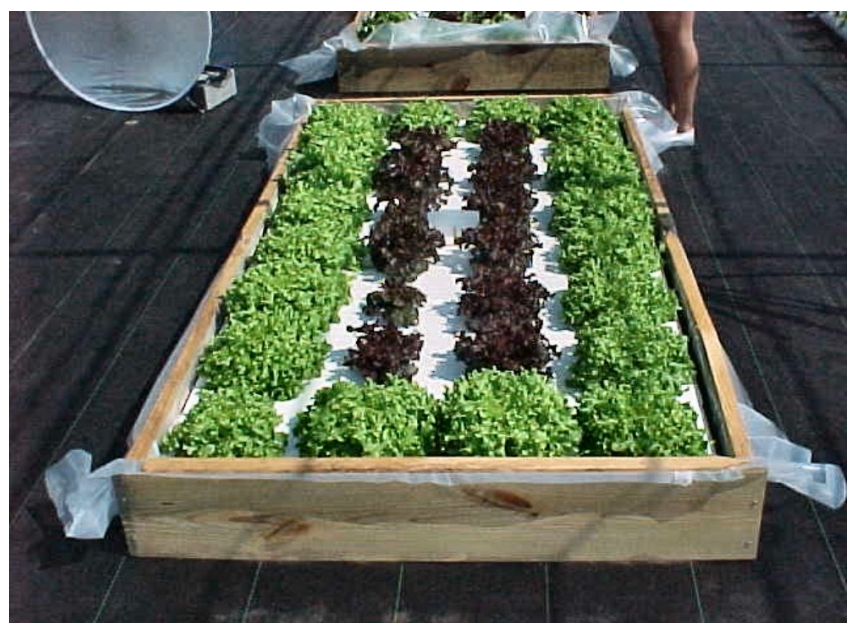

Figure 1. Lettuce in floating garden system.

\section{Construction Steps}

- Build a rectangular frame using 2-by-6-inch or 2-by-8-inch treated lumber. The frame should be 4 feet, 1 -inch wide by 8 feet, 1 -inch long. This size frame eliminates the need to trim the floating styrofoam, however, the size can be varied to suit personal needs.

- Line the frame with 6-mil polyethylene to form a trough to contain the nutrient solution. Be sure the site is level and free of any debris, which could puncture the polyethylene.

- Secure one end and side of the liner to the top edge of the frame with 1-by-2 inch furring strips or lattice using wood screws or small nails.

- Place a 4-by-8-foot sheet of 1 1/2 inch thick styrofoam insulation in the lined frame. Make sure the edges have sufficient room to allow the garden to move up and down. If necessary, adjust the frame to make it square with the styrofoam. The styrofoam sheet will create a floating platform in the wooden frame you have constructed.

1. this is document HS-943, a publication of the Horticultural Department, Florida Cooperative Extension Service, Institute of Food and Agricultural Sciences, University of Florida. Publication Date: March 2001. Revision Date: September 2003. Please visit the EDIS Web site at http://edis.ifas.ufl.edu.

2. Michael Sweat, county extension director, Baker County, Richard Tyson, extension agent II, Seminole County, and Bob Hochmuth, extension agent IV, North Florida Research and Education Center - Suwannee Valley, Cooperative Extension Service, Institute of Food and Agricultural Sciences, University of Florida, Gainesville, FL 32611.

The Institute of Food and Agricultural Sciences is an equal opportunity/affirmative action employer authorized to provide research, educational information and other services only to individuals and institutions that function without regard to race, color, sex, age, handicap, or national origin. For information on obtaining other extension publications, contact your county Cooperative Extension Service office. Florida Cooperative Extension Service/Institute of Food and Agricultural Sciences/University of Florida/Christine Taylor Waddill, Dean. 
- Fill the water garden with approximately 20 gallons of water. The water will form the polyethylene to the sides of the frame. Secure the other end and side of the liner to the top edge of the frame.

- Continue filling the water garden with water to a total depth of at least four inches. Keep track of the total gallons of water you add.

- Add water-soluble fertilizer, such as 20-20-20 with micronutrients, at a rate of 2 teaspoons of fertilizer for each gallon of water used in the water garden. In addition, add Epsom Salts (magnesium sulfate) at a rate of one teaspoon for each gallon of water. Use a soft broom to mix the water $\&$ fertilizer in the garden or premix all fertilizer in a bucket before adding to water garden (Figure 2).

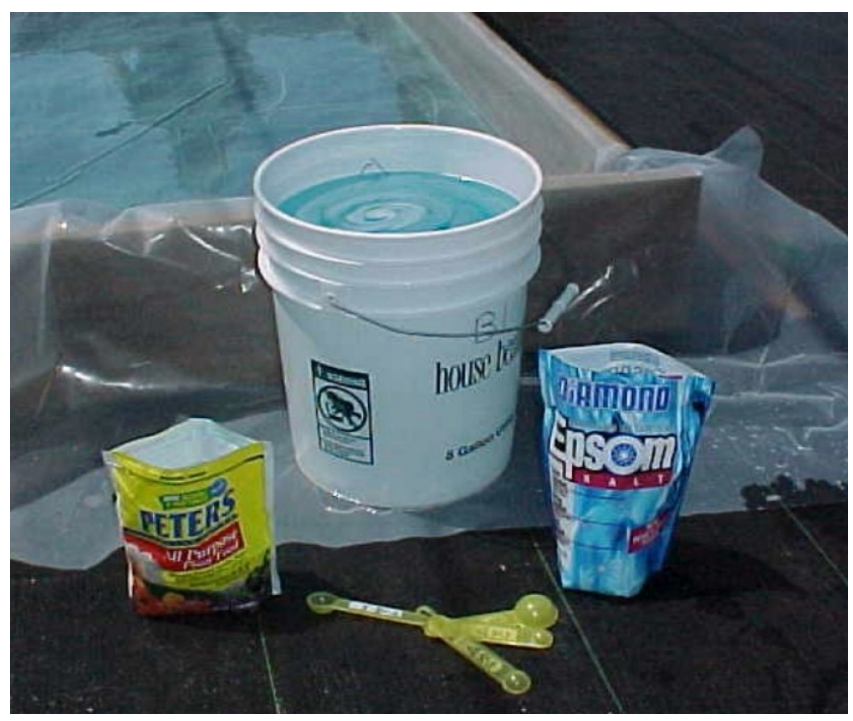

Figure 2. Nutrients needed for floating garden.

- Light rainfall will have little effect on the water garden; only extensive flooding would require fertilizer adjustment based on the amount of water added by rainfall. The solution in the garden needs to be replaced periodically for optimum production. You can grow two crops of salad greens in the same solution before changing the entire solution and starting with a new batch.

- Commercially available "net pots" (Figure 3) or styrofoam coffee cups with slits cut in the bottom may be used to hold the young seedlings.
- Use a hole saw or sharp knife to cut holes in the styrofoam. A 2 1/2-inch hole saw is needed to drill the correct-size holes in 1 1/2-inch thick styrofoam when using the 3" Net Pot or a styrofoam cup with slits cut in the bottom and trimmed at the top. Using 2" Net Pots will require a $13 / 4$-inch hole saw for the 1 1/2-inch styrofoam (Figure 4). The hole size should allow the bottom of a cup to be slightly below (1/8 inch) the underside of the styrofoam. It is very important that once the cups are placed in the holes, they do not extend down lower than 1/8 inch below the bottom of the styrofoam sheet! This allows the root mass to wick up water without being totally submerged, which might lead to drowning of the root and plant death.

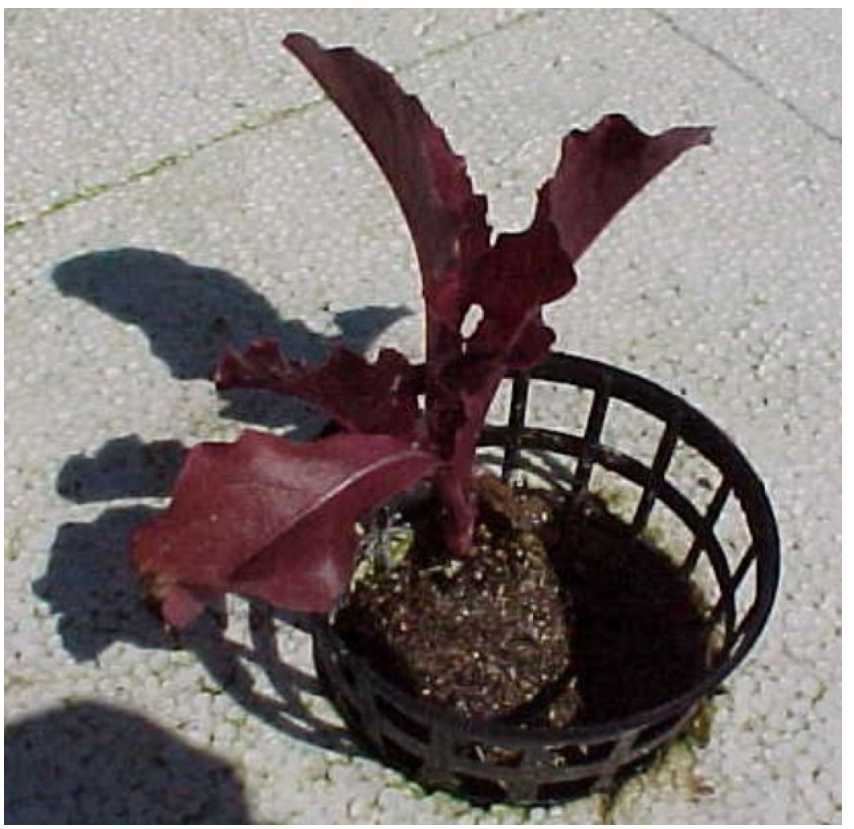

Figure 3. Lettuce transplant in net pot.

- Optimum plant spacing for most plants would be 6 inches from the sides and 12 inches apart to form 32 holes for planting.

- Transplants used in this system should be grown to be fully rooted in a typical soilless media. Transplants can be grown at home in many root ball shapes in a loose media, purchased from garden suppliers, or grown in compressed peet pellets.

- Place young starter transplants directly into the cups. Use toothpicks, if desired, to hold the transplant in an upright position. Do not remove the potting soil from the transplant. 


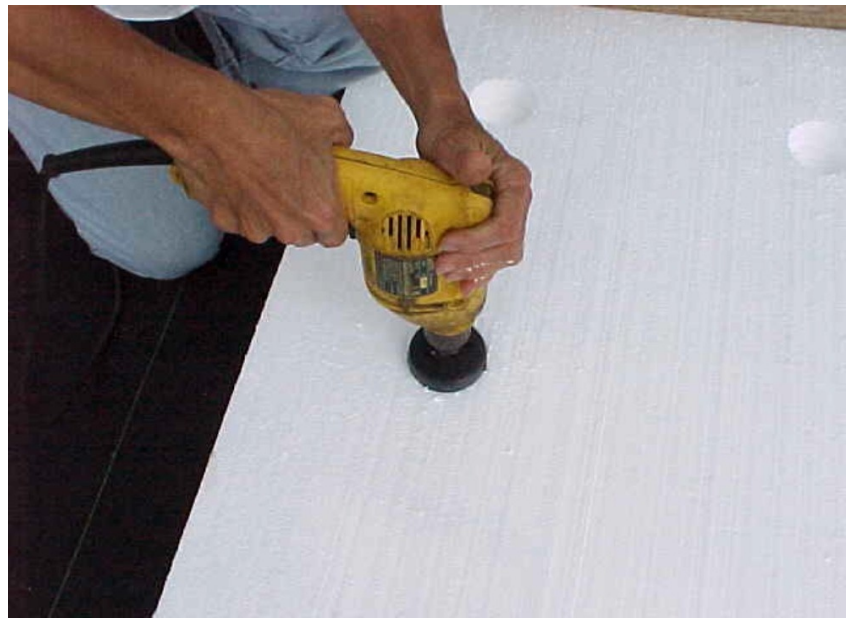

Figure 4. Drilling holes in styrofoam for transplants.

- After placing the young transplant in the net pot or styrofoam cup, do not add any potting mix or other material around the young transplant as this will keep the roots too wet and inhibit oxygen intake (Figure 5).

- Add extra water and fertilizer as needed to keep the styrofoam sheet floating on a minimum of 4-inches of solution.

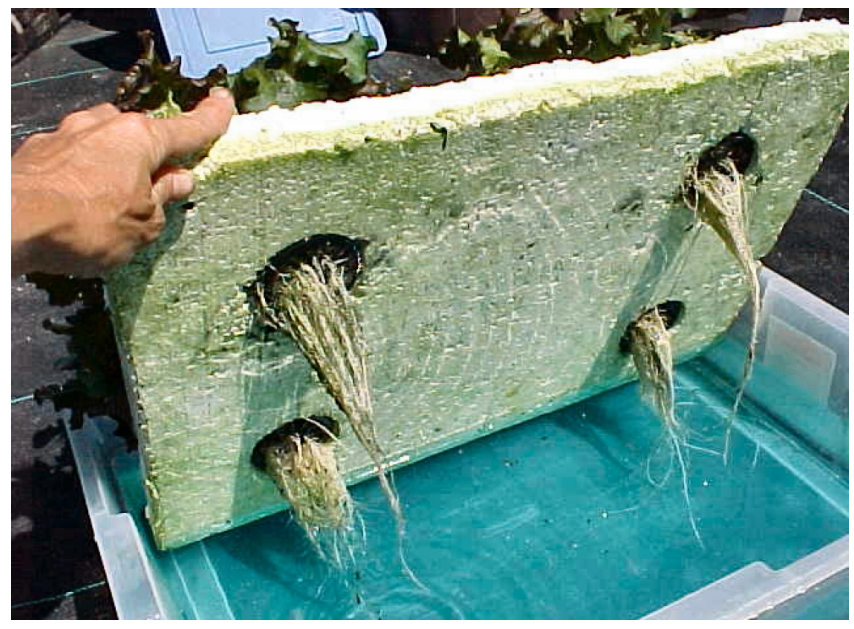

Figure 5. Hydroponic lettuce root system.

\section{Crops}

Several leafy salad crops (romaine, boston, bibb, $\&$ leafy lettuces, Figure 6) grow well during the cool season. There are fewer crop options for the warm season, however, basil and some cut-flowers, like Zinnia and sunflowers have done well. Other crops you could experiment with are watercress, cucumbers (requires trellis), herbs, and some flowers. Growing with floating systems does not override the normal challenges of gardening in the warm season in Florida.

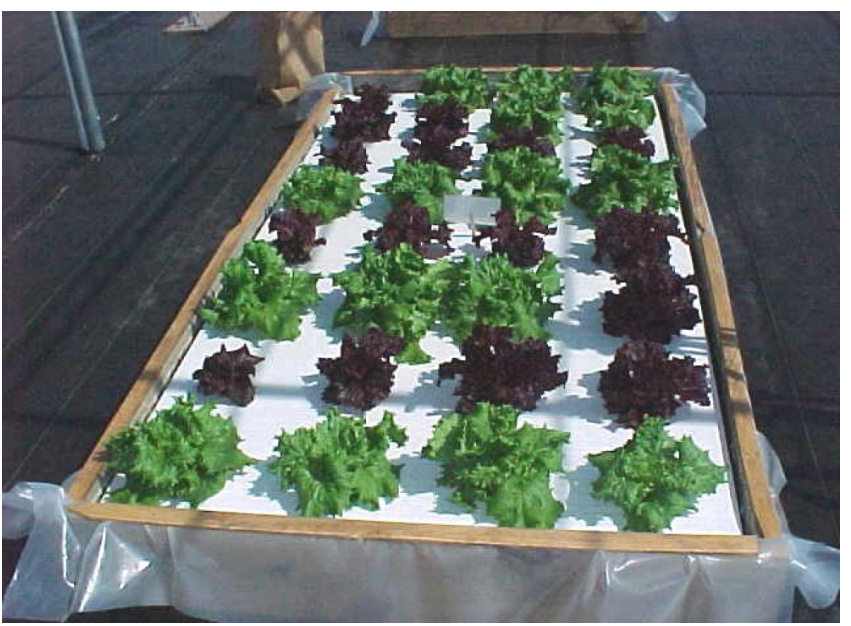

Figure 6. Healthy lettuce being grown in a standard $4 \times 8 \mathrm{ft}$ floating garden.

Not all crops do well in the floating gardens; however, small-rooted, short-season crops generally grow well. Crops that prefer wet rooting conditions grow better than those that prefer dry conditions. For example, watercress grows very well, and periwinkle does not grow as well in a floating garden.

\section{Container Choices}

This publication guides you in the steps to build a $4 \times 8 \mathrm{ft}$ floating garden using wood and a plastic liner. Many simple containers can also be used to make a floating garden. Examples include: children's pools (kiddie pools), small plastic storage containers, trash cans, and buckets. Many shapes and sizes of containers will work, but they should be able to maintain a 4-6 inch depth of nutrient solution for the best success.

\section{New Research}

Ongoing research with plants such as tomatoes in floating systems indicate that larger plants require more above-water rooting volume (more air-space) in order to produce successful yields. To produce more root mass above the water, you may want to test a system that uses two stacked styrofoam floats with holes drilled in the bottom one and all but a six-inch edge around the perimeter cut out of the top one. Fill the empty top float with perlite, vermiculite, or other 
hydroponic media and plant vegetables or flowers into it the same way you would plant a normal garden. Preliminary results show this method to be promising if starter fertilizer is used on the young plants until their roots reach the fertilized hydroponic solution below the floats.

\section{Additional Resources}

For more information on hydroponic production, please visit our website at http://nfrec-sv.ifas.ufl.edu. Residents in Florida can view a video on the topic of "Building a Hydroponic Floating Garden" by contacting the local County Extension office. A copy of this video may also be purchased for $\$ 15.00$, plus tax, by contacting the IFAS Bookstore at (352) 392-1764 or online at http://www.ifasbooks.ufl.edu.

\section{Hydroponic Suppliers}

\section{Aquatic Ecosystems, Inc. -}

http://aquaticeco.com 1-877-347-4788 - net pots, hobby kits, hydroponic supplies.

\section{Hydrogardens, Inc. -}

http://www.hydrogardens.com 1-800-634-6362 - net pots, hydroponic supplies.

Verti-Gro, Inc. - http://www.vertigro.com 1-352-347-9888 - vertical hydroponic gardening supplies.

CropKing, Inc. - http://www.cropking.com 1-800-321-5656 - hydroponic supplies, hobby greenhouses.

Worm's Way, Inc. - http://www.wormsway.com 1-800-283-9676 - hydroponic supplies, hobby kits.

\section{Simply Hydroponics -}

http://www.simplyhydro.com 1-727-531-5355 -

hydroponic supplies, hobby kits.

\section{Homegrown Hydroponics -}

http://www.growcrazy.com - 1-888-833-4769 hydroponic supplies, hobby kits, books, fertilizers etc.

Note: This is a partial list of suppliers of hydroponic materials and supplies. Mention of the above suppliers is not intended to be an endorsement of their product or a preference over other suppliers. 